\title{
OUTCOME OF TYPE I TYMPANOPLASTY IN TUBOTYMPANIC CHRONIC SUPPURATIVE OTITIS MEDIA IN RELATION TO SITE AND SIZE OF TYMPANIC MEMBRANE PERFORATION
}

\author{
Nitin V. Deosthale ${ }^{1}$, Priyanka Kumar ${ }^{2}$, Sonali P. Khadakkar ${ }^{3}$, Vivek V. Harkare ${ }^{4}$, Priti R. Dhoke ${ }^{5}$, Kanchan S. Dhote ${ }^{6}$, Rahul Varma ${ }^{7}$, \\ Prajakta S. Golhar ${ }^{8}$
}

1 Professor, Department of ENT, N.K.P Salve Institute of Medical Sciences and Research Centre, Nagpur. 2Junior Resident, Department of ENT, N.K.P Salve Institute of Medical Sciences and Research Centre, Nagpur. ${ }^{3}$ Senior Resident, Department of ENT, N.K.P Salve Institute of Medical Sciences and Research Centre, Nagpur. ${ }^{4}$ Professor and HOD, Department of ENT, N.K.P Salve Institute of Medical Sciences and Research Centre, Nagpur. ${ }^{5}$ Associate Professor, Department of ENT, N.K.P Salve Institute of Medical Sciences and Research Centre, Nagpur. ${ }^{6}$ Senior Resident, Department of ENT, N.K.P Salve Institute of Medical Sciences and Research Centre, Nagpur. 7 Junior Resident, Department of ENT, N.K.P Salve Institute of Medical Sciences and Research Centre, Nagpur. 8Junior Resident, Department of ENT, N.K.P Salve Institute of Medical Sciences and Research Centre, Nagpur.

ABSTRACT: AIM: To find out the relation between hearing loss with site and size of perforation and assessment of improvement in hearing and graft uptake following type I tympanoplasty in dry Tubotympanic Chronic Suppurative Otitis Media.

Study Design-Non-Randomized Experimental Study.

MATERIAL AND METHOD: This study was done in ENT OPD at Tertiary Health Care Institute of Central India. It was conducted from November 2012 to October 2014 on 46 patients having dry Tubotympanic Chronic Suppurative Otitis Media. Type 1 Tympanoplasty was done in all patients using temporalis fascia graft. All patients were followed up for 12 weeks postoperatively and evaluated for graft uptake and hearing improvement with respect to size and site of perforation. Results were analyzed statistically.

RESULTS: Complete graft uptake was seen in $86.46 \%$ patients. Graft uptake was more in small perforations than larger ones ( $p$ value=0.0008). Graft failure was more in subtotal perforation and perforations involving all four quadrants. Average Pure Tone hearing loss was more in Subtotal perforation (45.5dB) and perforations occupying all four quadrants (41.27\%). Hearing loss was more in Posteroinferior quadrant perforations as compared to Anteroinferior quadrant perforations and so also the hearing improvement after type I tympanoplasty.

CONCLUSION: There was a relationship between size and site of perforation with hearing impairment in tubotympanic type of CSOM. Posterior quadrant perforations were having more hearing loss and greater hearing improvement after surgery as compared to those with anterior quadrant perforation. Rate of graft uptake was directly proportional to size of perforation.

KEYWORDS: Chronic Suppurative Otitis Media; Tympanic Membrane Perforation; Pure Tone Audiometry; Tympanoplasty.

HOW TO CITE THIS ARTICLE: Nitin V. Deosthale, Priyanka Kumar, Sonali P. Khadakkar, Vivek V. Harkare, Priti R. Dhoke, Kanchan S. Dhote, Rahul Varma, Prajakta S. Golhar. "Outcome of Type I Tympanoplasty in Tubotympanic Chronic Suppurative Otitis Media in Relation to Site and Size of Tympanic Membrane Perforation." Journal of Evolution of Medical and Dental Sciences 2015; Vol. 4, Issue 93, November 19; Page: 15834-15838, DOI: 10.14260/jemds/2015/2295.

INTRODUCTION: Chronic Suppurative Otitis Media (CSOM) is a most common cause of hearing loss in developing countries because of lack of specialized medical care, malnutrition and poor hygienic condition. Tubotympanic type of CSOM is characterised by perforation of pars tensa. Tympanic membrane plays important role in middle ear transformer mechanism.

It has been a general view that hearing loss increases with the size of perforation. The site of perforation in the tympanic membrane also has significant impact on magnitude of hearing loss. ${ }^{1}$

Financial or Other, Competing Interest: None.

Submission 24-10-2015, Peer Review 26-10-2015,

Acceptance 09-11-2015, Published 17-11-2015.

Corresponding Author:

Dr. Nitin V. Deosthale,

K-28, Bharat Nagar,

Amravati Road,

Nagpur-440033,

Maharashtra.

E-mail:nvdeosthale@rediffmail.com

DOI:10.14260/jemds/2015/2295.
Posterior perforations have poor hearing than anterior ones because of direct exposure of round window to sound waves. ${ }^{1}$

Perforation at or near the site of attachment of tympanic membrane has more severe effect than those of same size at different site. However some authors believe that there is no significant effect associated with location of perforation. ${ }^{2}$

This study was done with the aim to find out the relation between hearing loss with site and size of perforation and assessment of improvement in hearing and graft uptake following type I tympanoplasty in dry tubotympanic Chronic Suppurative Otitis Media.

MATERIAL AND METHODS: The study was conducted in the Department of ENT, at Tertiary Health Care Institute of Central India for the duration of 24 months from November 2012 to October 2014. Every consecutive patient of Chronic Suppurative Otitis Media (CSOM) fulfilling inclusion and exclusion criteria were included in the study. The Patients were selected based on the following criteria: 
1. Patients with age group of 16 to 60 years of either sex with Tubotympanic disease (Safe CSOM) having dry ear for minimum period of 6 weeks.

2. Patients with small, moderate, large or subtotal central perforation.

3. Patients with pure conductive hearing loss and good cochlear reserve.

4. Patients with normal or partially impaired Eustachian tube function.

Patients with active discharge, traumatic perforation, post-ventilation tube insertion perforation, and those with altered ossicular status detected on Pure Tone Audiometry and intraoperatively, who required Tympanoplasty other than Type I, were excluded from the study.

These selected patients were subjected to clinical, radiological and laboratory investigations required for Preanaesthetic fitness. Otomicroscopy was done in all cases.

Tympanic membrane was divided into four quadrants: Anterosuperior (AS), Anteroinferior (AI), Posterosuperior (PS) and Posteroinferior (PI).

\section{Size of Tympanic membrane perforation is defined as follows:}

Small Perforation: Occupying less than the size of one quadrant of tympanic membrane. Medium perforationOccupying more than the size of one quadrant but less than two quadrants. Large perforation-Occupying more than the size of two quadrants but less than three quadrants. Subtotal perforation-Occupying more than the size of three quadrants.

Before undergoing surgery, all patients underwent Eustachian tube function assessment by "Interacoustic AT 235 impedance audiometer" by Toynbee test. ${ }^{3}$ Hearing assessment of all patients was carried out one day prior to the surgery with the help of Pure Tone Audiometry using "ELKON eda Giga 3 audiometer." The technique followed was Carhart and Jerger's 5 up and 10 down method. 4 The tests were performed in the acoustically treated room with no ambient noise. In the patients with bilateral ear disease, the ear with more hearing loss was operated.

The air and bone conduction threshold averages were calculated by taking the average of 500, 1000, 2000 and 4000 $\mathrm{Hz}$ frequencies. The Air Bone Gap (ABG) was calculated by taking difference between air conduction and bone conduction thresholds. The air and bone conduction thresholds were recorded both pre-and postoperatively. Type I Tympanoplsty was done in all patients by postaural approach under Local Anaesthesia with I.V. sedation or General Anaesthesia using temporalis fascia graft as a graft material.

Postoperatively, all the patients were put on injectable antibiotics for 1 day followed by oral antibiotics, analgesics and antihistaminics for 7 days. Sutures were removed on $7^{\text {th }}$ day. All cases were followed up on OPD basis after $1^{\text {st }}$ week, $2^{\text {nd }}$ week, $4^{\text {th }}$ week, $8^{\text {th }}$ week and $12^{\text {th }}$ week. Otoscopy was done to assess the graft status and presence of any discharge at every follow-up. Postoperative hearing assessment with Pure Tone Audiometry was done at the end of 12 weeks. The presence of any complication was noted and treated simultaneously. The post-operative ABG closure was calculated by taking difference between pre-operative $A B G$ and post-operative $\mathrm{ABG}$ of average frequencies of 500, 1000, 2000 and 4000 Hz. 1,5

From the air conduction threshold level, the deafness can be graded into several categories like below. ${ }^{6}$ $<25$ dB-Normal Hearing,

26 - $40 \mathrm{~dB}$ - Mild hearing impairment,

$41-60 \mathrm{~dB}$ - Moderate hearing impairment,

$61-70 \mathrm{~dB}$-Severe hearing impairment,

71 - 90dB - Profound hearing impairment,

91dB and above - Total deafness.

For the purpose of study: Successful graft uptake is stable, healed, clinically intact tympanic membrane. Graft failure includes residual perforation, reperforation, medialization of graft, and complete graft failure. All the results were analyzed statistically.

RESULTS: The present study was carried out in 46 patients of dry tubotympanic type Chronic Suppurative Otitis Media in two years' period. Out of 46 patients, 22 were males and 24 females. The mean age was $27.87 \pm 9.79$ years and maximum number of patients $(45.65 \%)$ were in the age group of $21-30$ years; 41 patients $(89.14 \%)$ had unilateral disease while 5 $(10.87 \%)$ had bilateral disease. Otorrhoea was the commonest complaint in all patients (100\%) followed by hearing loss in 39 (84.78\%) patients.

On ascertaining the size of tympanic membrane perforation, it was observed that $9(19.57 \%)$ patients had small central perforation, $22(47.83 \%)$ had moderate, 11 (23.91\%) had large and $4(8.69 \%)$ had subtotal perforation. Maximum number of patients (17 patients) had two quadrant perforation followed by four quadrant perforation (12 patients), single quadrant perforation ( 9 patients) and three quadrant perforation (8 patients) in decreasing order.

Graft uptake according to Size and Site of perforation: After surgery, at the end of 12 weeks' follow-up, out of 46 patients, 40 patients (86.96\%) had complete graft uptake and 6 patients $(13.04 \%)$ had graft failure. Graft uptake results were excellent i.e. $100 \%$ in small sized perforation involving single quadrant as compared to subtotal perforation $(25 \%$ graft uptake) as shown in Table I. Smaller the perforation, graft uptake rate was more. (chi-square Test $=16.54$, $\mathrm{p}$ value= 0.0008). Out of 6 graft failures, 4 had medialization of graft and 2 had residual perforation (Table II).

None of the patient had complete graft failure. Medialization of graft was seen in 1 patient of moderate sized perforation, 2 patients of large perforation and 1 patient of subtotal perforation. Two patients who had residual perforation were of subtotal size involving all four quadrants. According to the site of perforation, graft failure was more in perforations involving all four quadrants (AS+AI+PS+PI), i.e., in 3 patients of which 1 had medialization of graft and 2 had residual perforation (Table II).

Hearing Improvement according to Size and Site of perforation: On assessing the hearing loss on Pure Tone Audiometry, average preoperative Pure Tone hearing loss (Air-Bone Gap) was 35.86dB (SD+/-5.81). At the end of 12 weeks after surgery, the average Pure tone hearing loss (AirBone Gap) was 22.73dB (SD+/-2.87). So the average hearing 
improvement after surgery was of $13.05 \mathrm{~dB}(\mathrm{SD}+/-5.06)$.

As shown in Table III, Pure Tone average hearing loss (ABG) was found to be more in subtotal perforation, i.e., $45.5 \mathrm{~dB}$ followed by hearing loss in large perforation (38.48dB), moderate perforation (35.95dB), and small perforation $(28.13 \mathrm{~dB})$. After surgical treatment, average hearing improvement was $6.03 \mathrm{~dB}$ in small perforation. In Subtotal perforation average hearing improvement was found to be maximum i.e., $19.25 \mathrm{~dB}$ as preoperative hearing loss was also more in those cases (Table III).

On assessing the hearing level according to the site of perforation, we observed that single quadrant perforation in posterior quadrant had more hearing loss as compared to anterior perforation. Perforations in AS quadrant had average hearing loss of $25 \mathrm{~dB}$ and $\mathrm{AI}$ quadrant perforations had average hearing loss of $24.7 \mathrm{~dB}$ while in PI quadrant perforations it was $33.92 \mathrm{~dB}$ as shown in Table IV. On comparing the hearing loss between AI quadrant and PI quadrant perforations by using unpaired t-test, the difference was statistically significant ( $p$ value $=0.0004$ ). Similarly, two quadrant posterior perforations in PS+PI had more Pure Tone average hearing loss $(36.8 \mathrm{~dB})$ as compared to anterior quadrant $\mathrm{AS}+\mathrm{AI}$ perforation $(30.67 \mathrm{~dB})$ and difference between the two was statistically significant (Unpaired t-test, $p$ value $=0.016$ ). Perforation occupying all four quadrants $(\mathrm{AS}+\mathrm{AI}+\mathrm{PS}+\mathrm{PI})$ had average hearing loss of $41.27 \mathrm{~dB}$. (Table IV).

Postoperatively, after 12 weeks follow-up, Hearing improvement was more in PI quadrant perforations (11.16dB) as compared to AS quadrant perforations (4dB) and AI quadrant perforations (3.5dB). All four quadrant perforation (AS+AI+PS+PI) had shown average hearing improvement of $17.10 \mathrm{~dB}$ which was more as compared to three quadrants, two quadrants or single quadrant perforation as shown in Table IV.

DISCUSSION: Chronic Suppurative Otitis Media with perforation of pars tensa is very common worldwide and is one of the main causes of conductive hearing loss in developing countries like India. The aim of management of such cases is to provide safe and dry ear and to restore the hearing mechanism. Sakagami et al. ${ }^{7}$ in his study of CSOM observed that $90.1 \%$ (82 out of 91) cases had tympanic membrane perforation and ossicular chain was absolutely intact in them. Therefore timely management provides better hearing results and protects middle ear cleft from further complications. In this study, an effort was made to study the effect of site and size of perforation on degree of hearing loss and to assess the graft uptake and improvement in hearing after type I tympanoplasty in relation to site and size of perforation.

Hearing loss in relation to size of perforation: In general, larger the size of perforation greater is the hearing impairment. In our study, hearing loss was found to be directly proportional to the size of perforation. This observation is consistent with the studies of Vos SE et al. ${ }^{8}$ Walter PA. ${ }^{9}$ et al., Kumar et al. ${ }^{10}$ and Vaidya $S$ et al. ${ }^{11}$ The larger perforations result in loss of middle ear and mastoid volume, decrease in areal ratio; also there is more chance of diminish in the phase effect due to exposure of the round and the oval window to the sound pressure.

Hearing loss in relation to site of perforation: Average hearing loss in single quadrant perforations in AI quadrant and PI quadrant were compared and it was seen that hearing loss was more in cases of PI quadrant perforations and the difference was statistically significant ( $p$ value 0.0004 ). In the study of Kumar et al., ${ }^{10}$ average hearing loss in AI quadrant perforation was $26.6 \mathrm{~dB}$ and that in PI quadrant was $32.4 \mathrm{~dB}$. Vaidya $\mathrm{S}$ et al. ${ }^{11}$ found average hearing loss of $30.36 \mathrm{~dB}$ in $\mathrm{AI}$ quadrant perforations and $39.10 \mathrm{~dB}$ in PI quadrant perforations.

In two quadrant perforations, Kumar et al. ${ }^{10}$ found average hearing loss of $28.12 \mathrm{~dB}$ in $\mathrm{AS}+\mathrm{AI}$ quadrant perforations and that of $36.6 \mathrm{~dB}$ in PS+PI quadrant perforation. According to the study of Vaidya $S$ et al. ${ }^{11}$ average hearing loss in AS+AI quadrant perforation was $37.12 \mathrm{~dB}$, while in PS+PI perforation, it was $46.83 \mathrm{~dB}$. Our findings are consistent with both these studies. Unlike this, Mehta et al.12 and Oluwole $\mathrm{M}$ et al. $^{13}$ did not observe significant difference in average hearing loss in anterior versus posterior quadrant perforations.

In our study, all four quadrant perforations had shown average hearing loss of $41.27 \mathrm{~dB}$ which is consistent with Kumar et al. study. ${ }^{10}(44.6 \mathrm{~dB})$ and Vaidya $S$ et al. ${ }^{11}$ study (48.88dB).

Postoperative hearing improvement in relation to size of perforation: In our study average hearing improvement was more in subtotal perforation $(19.25 \mathrm{~dB})$ as compared to small perforation $(6.03 \mathrm{~dB})$. Vidya $S$ et al. ${ }^{11}$ observed average hearing improvement of $14.03 \mathrm{~dB}$ in small sized perforation, $16.08 \mathrm{~dB}$ hearing improvement in medium sized perforation, $15 \mathrm{~dB}$ in large sized perforation and $16.25 \mathrm{~dB}$ hearing improvement in subtotal perforation.

Postoperative hearing improvement in relation to site of perforation: In our study, average hearing improvement was more in PI quadrant perforation than AS and AI quadrant perforation. Average hearing improvement was greater in perforations involving all four quadrants $(\mathrm{AS}+\mathrm{AI}+\mathrm{PS}+\mathrm{PI})$. These results are consistent with Vaidya et al. ${ }^{11}$ study, in which average hearing improvement in PI quadrant perforation was of $17.04 \mathrm{~dB}$. In AS quadrant perforation, hearing improvement was of 12.94 and in all four quadrant perforation, hearing improvement was of $16 \mathrm{~dB} .{ }^{11}$

Graft uptake in relation to size and site of perforation: In our study, we have considered medialization of graft, residual perforation and complete graft failure and reperforation as graft failures. We have observed that complete graft uptake was in $86.96 \%$ patients and failure in $13.04 \%$ patients. Graft failure was more in larger perforations than small ones and those occupying all four quadrants.

In Vaidya $\mathrm{S}$ et al. ${ }^{11}$ study, graft intact was in $86 \%$ cases and residual perforation in $14 \%$ cases. In his study residual perforation was more in subtotal perforation (37.5\%) and those involving all four quadrants $(33.33 \%)$. In Kumar et al. ${ }^{10}$ study, graft was intact in $80 \%$ patient and rejected in $20 \%$ 
patients. In Kumar et al.10 study, graft uptake rate had not been not studied in relation to size and site of perforation.

CONCLUSION: We have observed that there is a relationship between size and site of perforation with hearing impairment in tubotympanic type of CSOM. The larger the perforation greater is the hearing loss. Average hearing improvement was also found to be greater in larger perforations.

Posterior quadrant perforations were having more hearing loss and greater hearing improvement after surgery as compared to those with anterior quadrant perforation. Rate of graft uptake is directly proportional to size of perforation.

\section{REFERENCES:}

1. Mahajan M, Kafle P, Bista M, Shrestha S, Toran KC. Observation of hearing loss in patients with chronic suppurative otits media tubotympanic type. KUMJ, 2009,7(28):397-401.

2. Ibekwe TS, Nwaorgu OG, Ijaduola TG. Correlating the site of tympanic membrane perforation with hearing loss. BMC Ear Nose Throat Disorder, 2009;9(1):1.

3. Biswas A. Eustachian tube function test:A new dimension in the management of CSOM. IJO-HNS 1999 April-June; 51(2).23-28.

4. Livingstone G, Millar H, Results of tympanoplasties, 1956-1959. J Laryngol Otol 1961; 75: 669-78.

5. Shrestha BL, Bhusal CL, Bhattarai H. Comparison of preand post-operative hearing results in canal wall down mastoidectomy with type three tympanoplasty. J Nepal Med Assoc 2008 Oct-Dec; 47(172): 224-7.
6. Ministry of Social Justice and Empowerment, Govt. of India. Sub-Guidelines for evaluation of various disabilities and procedure for certification. New Dehli; 1st June 2001: No.16-18/97-NI.

7. Sakagami M, Maeda A, Node A, Sone M, Mishiro Y. Long term observation on hearing change in patients with chronic otitis media. Auris Nasus Larynx. 2000:27(@):117-120.

8. Vos SE, Rosowski JJ, Merchant SN, Peake WT. How do tympanic membrane perforations cause conductive hearing loss. Session J, Podium. 1998:263.

9. Walter PA, Clell WH. Tympanic membrane perforation. Effect on Audiogram. Arch Otolaryngol. 1972;95(6):50620.

10. Kumar M, Chilke D, Puttewar MP. Clinical profile of tubotympanic CSOM and its management with special reference to site and size of tympanic membrane perforartion, Eustachian tube function and three flap tympanoplasty. Indian J otolaryngol Head Neck Surg. 2012;64(1):5-12.

11. Vaidya S, Sharma JK, Singh G. Study of outcome of tympanoplasties in relation to size and site of tympanic membrane perforation. 2014;66(3):341-346.

12. Mehta RP, Rosowske JJ, Voss SE, O'Neil E, Merchant SN. Determinants of hearing loss in perforations of tympanic membrane. Otol Neurotol. 2006;27(2):136143.

13. Oluwole M, Mills RP. Tympanic membrane perforations in children. International Journal of paediatric Otorhinolaryngology. 1996;36:117-123.

\begin{tabular}{|c|c|c|c|}
\hline \multirow{2}{*}{ Size of Perforation } & \multirow{2}{*}{ No. of Ears } & $\begin{array}{c}\text { Successful } \\
\text { No. (\%) }\end{array}$ & $\begin{array}{c}\text { Failure } \\
\text { No. (\%) }\end{array}$ \\
\cline { 2 - 4 } & 9 & $9(100 \%)$ & 0 \\
\hline Small central & 22 & $21(95.45 \%)$ & $1(4.54 \%)$ \\
\hline Medium central & 11 & $9(81.81 \%)$ & $2(18.18 \%)$ \\
\hline Large central & 4 & $1(25 \%)$ & $6(75 \%)$ \\
\hline Subtotal perforation & 46 & $40(86.96 \%)$ & $6(13.04 \%)$ \\
\hline Total patients & \multicolumn{2}{|c|}{$\begin{array}{c}\text { Table I: Distribution of Patients According to Size of } \\
\text { 12 weeks Postoperatively (n=46) }\end{array}$} \\
\hline \multicolumn{3}{|c|}{} \\
\hline
\end{tabular}

Chi square Test $=16.54, \mathrm{P}$ value $=0.0008$ (Highly Significant)

${ }^{*}$ p value $<0.05$ - significant

\begin{tabular}{|c|c|c|c|}
\hline \multirow{2}{*}{ Graft Failure } & $\begin{array}{c}\text { Size of } \\
\text { Perforation }\end{array}$ & $\begin{array}{c}\text { Site of } \\
\text { Perforation }\end{array}$ & $\begin{array}{c}\text { No. of Patients } \\
\text { of Graft Failures }\end{array}$ \\
\hline \multirow{3}{*}{ Medialization } & Moderate & AS+AI & 1 \\
\cline { 2 - 4 } & Large Perforation & AS+AI+PI & 2 \\
\cline { 2 - 4 } & Subtotal Perforation & AS+AI+PS+PI & 2 \\
\hline Residual Perforation & Subtotal Perforation & AS+AI+PS+PI & 2 \\
\hline \multicolumn{3}{c}{$\begin{array}{c}\text { Table II: Status of Graft Amongst Graft Failure Patients According } \\
\text { to Site and Site of Perforation at the End of 12 weeks Postoperatively }\end{array}$} \\
\hline
\end{tabular}




\begin{tabular}{|c|c|c|c|c|c|c|}
\hline $\begin{array}{c}\text { Size of } \\
\text { Perforation }\end{array}$ & $\begin{array}{c}\text { No. of } \\
\text { Ears }\end{array}$ & $\begin{array}{c}\text { Average } \\
\text { Preoperative } \\
\text { ABG } \pm \text { SD\# (dB) }\end{array}$ & $\begin{array}{c}\text { Average } \\
\text { Postoperative } \\
\text { ABG } \pm \text { SD\# (dB) }\end{array}$ & $\begin{array}{c}\text { Average Hearing } \\
\text { Improvement } \\
\text { (ABG Closure) } \pm \\
\text { SD" } \text { (dB) }\end{array}$ & $\begin{array}{c}\text { Paired T- } \\
\text { test }\end{array}$ & P value* $^{*}$ \\
\hline Small & 9 & $28.13 \pm 5.14$ & $21.78 \pm 2$ & $6.03 \pm 4.05$ & 4.65 & 0.0009 \\
\hline Moderate & 22 & $35.95 \pm 2.85$ & $22.23 \pm 2.88$ & $13.72 \pm 3.11$ & 11.70 & $<0.0001$ \\
\hline Large & 11 & $38.48 \pm 3.26$ & $23.27 \pm 3$ & $15.20 \pm 3.47$ & 12.07 & $<0.0001$ \\
\hline Subtotal & 4 & $45.5 \pm 2.46$ & $26.25 \pm 1.44$ & $19.25 \pm 3.56$ & 25.77 & $<0.0001$ \\
\hline \multicolumn{7}{|c|}{ Table III: Hearing Improvement According to the } \\
\hline
\end{tabular}

*p value $<0.05$-Statistically significant \#SD- Standard Deviation

\begin{tabular}{|c|c|c|c|c|c|c|}
\hline $\begin{array}{l}\text { Quadrant } \\
\text { Involved }\end{array}$ & $\begin{array}{l}\text { No. of } \\
\text { Ears }\end{array}$ & $\begin{array}{c}\text { Average } \\
\text { Preoperative } \\
\mathbf{A B G} \pm \mathbf{S D}^{\#}(\mathrm{~dB})\end{array}$ & $\begin{array}{c}\text { Average } \\
\text { Postoperative } \\
\text { ABG } \pm \text { SD }^{\#}(\mathrm{~dB})\end{array}$ & $\begin{array}{c}\text { Average Hearing } \\
\text { Improvement }(\mathrm{ABG} \\
\text { Closure }) \pm \mathrm{SD}^{\#}(\mathrm{~dB})\end{array}$ & $\begin{array}{l}\text { Paired T- } \\
\text { test }\end{array}$ & P value* \\
\hline AS & 1 & 25 & 21 & 4 & - & - \\
\hline $\mathrm{AI}$ & 5 & $24.7 \pm 0.33$ & $21.35 \pm 1.26$ & $3.35 \pm 0.99$ & 5.75 & 0.004 \\
\hline PS & 0 & $\overline{0}$ & 0 & 0 & - & - \\
\hline PI & 3 & $33.92 \pm 3.09$ & $22.75 \pm 3.26$ & $11.16 \pm 2.02$ & 4.30 & 0.12 \\
\hline $\mathrm{AS}+\mathrm{AI}$ & 3 & $30.67 \pm 2.02$ & $20 \pm 2.91$ & $10.67 \pm 1.53$ & 5.21 & 0.006 \\
\hline PS+PI & 5 & $36.8+2.77$ & $21.75+1.45$ & $15.05+2.43$ & 10.76 & $<0.0001$ \\
\hline $\mathrm{AI}+\mathrm{PI}$ & 9 & $36.94+2.45$ & $23.47 \pm 4.89$ & $13.47 \pm 3.60$ & 7.38 & $<0.0001$ \\
\hline $\mathrm{AS}+\mathrm{AI}+\mathrm{PI}$ & 3 & $34.33 \pm 1.15$ & $22.17 \pm 1.59$ & $12.17 \pm 1.42$ & 10.73 & $<0.004$ \\
\hline $\mathrm{PS}+\mathrm{PI}+\mathrm{AI}$ & 5 & $37.9 \pm 1.92$ & $22.7 \pm 3.27$ & $15.2 \pm 2.25$ & 8.96 & $<0.0001$ \\
\hline $\mathrm{AS}+\mathrm{AI}+\mathrm{PS}+\mathrm{PI}$ & 12 & $41.27+4.14$ & $24.17 \pm 2.87$ & $17.10 \pm 3.80$ & 11.75 & $<0.0001$ \\
\hline \multicolumn{7}{|c|}{$\begin{array}{l}\text { Table IV: Hearing Improvement According to the Site } \\
\text { of Perforation } 12 \text { weeks after Type I Tympanoplasty. }\end{array}$} \\
\hline
\end{tabular}

*p value $<0.05$ - Statistically significant \#SD- Standard Deviation 